DOI 10.37882/2223-2982.2020.12-2.10

\title{
ТРАДИЦИОННЫЕ И ИННОВАЦИОННЫЕ ТЕХНОЛОГИИ В ПРОФЕССИОНАЛЬНОЙ ПОДГОТОВКЕ ЛИНГВИСТОВ-ПЕРЕВОДЧИКОВ
}

\section{TRADITIONAL AND INNOVATIVE TECHNOLOGIES IN THE PROFESSIONAL TRAINING OF LINGUISTS-TRANSLATORS \\ I. Getskina}

Summary: The article analyzes the use of traditional and innovative technologies in the professional training of linguists and translators. It is noted that in the modern educational environment, such blended learning involves the use of information and educational resources, which allows you to simultaneously use the strengths of full-time education. The attitude of students to the use of traditional and innovative technologies in professional training is clarified. To conduct the research, the author used a survey method to collect and analyze personal information about respondents. The information collected expresses the students' opinion on professional translation studies through a combination of traditional and innovative teaching approaches.

Keywords: innovative educational technologies, traditional educational technologies, blended learning, translation studies, professional training, survey.

\section{Введение}

Л юбая педагогическая технология, независимо от того, имеет ли она традиционный или инновационный характер, направлена на то, чтобы раскрыть творческий потенциал учащихся и создать оптимальные условия для их личностного развития. В научно-педагогической литературе существует множество подходов к раскрытию понятия «педагогическая технология». В общераспространенном смысле педагогическая технология представляет собой определенную модель педагогического процесса, в рамках которого преподаватель разрабатывает комплекс учебных целей и задач, продумывает методы и приемы работы с учащимися, учебно-методическое обеспечение, которое может стать необходимой теоретической базой для успешного конечного результата.

На сегодняшний день также существует несколько классификаций педагогических технологий, среди которых мы выделим ту, которая базируется по принципы новизны применяемых методов и подходов обучения: инновационные и традиционные технологии.
Гецкина Инна Борисовна

к.филол.н., дочент, ФГБОУ ВО «Чувашский государственный университет им. И.Н. Ульянова»

igets68@gmail.com

Аннотация: В статье анализируется использование традиционных и инновационных технологий в профессиональной подготовке лингвистовпереводчиков. Отмечено, что в современной образовательной среде такое смешанное обучение предполагает использование информационных и образовательных ресурсов, что позволяет одновременно использовать сильные стороны очного обучения.

Уточняется отношение студентов к использованию традиционных и инновационных технологий при профессиональной подготовке. Для проведения исследования автор использовал метод опроса для сбора и анализа личной информации о респондентах. Собранная информация выражает мнение студентов о профессиональной переводоведческой подготовке с помощью сочетания традиционных и инновационных подходов обучения.

Ключевые слова: инновационные образовательные технологии, традиционные образовательные технологии, смешанное обучение, переводоведение, профессиональная подготовка, опрос.

Инновации рассматриваются не только как новые разработанные подходы и методы обучения, но и как способ повышения результативности учебного процесса. Одновременно мы можем рассматривать педагогические технологии как результат передовых педагогических исследований и авторских разработок (как индивидуальных, так и коллективных), которые уже получили практическое обоснование и значимость.

Таким образом, аккумулируя вышесказанное, мы можем сказать, что инновационные педагогические технологии - это совокупность новоразработанных форм, способов и подходов к педагогическому процессу, которые имеют под собой цель его усовершенствование, усиление мотивации учащихся изучать предлагаемый материал и создание положительной атмосферы на учебных занятиях.

Цель исследования - проанализировать применения традиционных и инновационных технологий обучения в профессиональной подготовке лингвистов-переводчиков. 


\section{Материалы и методы}

Использовался комплекс общенаучных теоретических, эмпирических и статистических методов, а именно: синтез, концептуализация теоретических знаний для формирования основных принципов работы; систематический анализ научных работ по проблеме исследования, метод опроса с целью сбора и анализа личной информации респондентов. Собранная информация выражала мнение студентов о применении традиционных и инновационных технологий при их профессиональной переводческой подготовке.

\section{Результаты исследования}

На сегодняшний день существует множество информационных технологий, среди которых можно выделить технологии, предполагающие активацию игровой деятельности учащихся; технологии, направленные на моделирование конкретных жизненных ситуаций; технологии проблемного обучения, а также технологию, которая ставит перед собой цель развитие критического мышления у учащихся.

Если мы сравним инновационные и традиционные технологии по их педагогическому потенциалу, направленности, то мы увидим между ними концептуальное противоречие, т.к. будут существенно отличаться от способа взаимодействия преподавателя с учащимися, от способа подачи и усвоения учащимися материала и от способов мониторинга итогов учебного процесса. Тем не менее, между такими технологиями можно выделить теоретическую связь.

Инновационные технологии при всех их преимуществах не имеют глубокой фундаментальной основы, чего нельзя сказать о традиционных педагогических технологиях. Преимущество традиционных технологий заключается в том, что разработанные в их рамках подходы к обучению, методы организации лекционных и практических занятий, написания квалификационных работ складывались на протяжении многих веков. Закономерным является следствие, что все инновационные технологии базируются на традиционных подходах обучения; и какая-либо инновационная технология не может охватить все компоненты образовательного процесса.

Понятно, что преподавание иностранных языков для лингвистов-переводчиков существенно отличается от преподавания студентам других-специальностей.

Сравнивая обучение в языковых и неязыковых университетах, методист И.М. Берман считает, что в первом случае язык осваивается как средство общения и изучается как система средств выражения. Во втором случае язык преподается только как средство общения, кото- рое реализуется в речи. Теоретическая информация используется только в той степени, в которой она может помочь в овладении языком.

Основываясь на исследовании И.М. Бермана, мы можем выделить следующие черты обучения иностранному языку переводчиков-лингвистов:

- практический характер образовательного процесса. Студенты имеют четко обозначенные цели изучения иностранного языка и приемов перевода. В таком случае иностранный язык играет роль не только средства коммуникации, но и профессионального взаимодействия. Помимо грамматических, синтаксических, лексикологических особенностей языка студенты усваивают способы адекватной передачи культурологических особенностей языка при переводе. В дополнение ко всему, студенты-лингвисты изучают профильную литературу по соответствующей дисциплине, в сфере которой они предполагают дальше работать (юриспруденция, медицина, строительное дело). Таким образом, в обучении студентов лингвистов-переводчиков превалирует междисциплинарный подход;

- сохранение преемственности между школьным и университетским образованием. Знания, полученные студентами еще в школьные годы, служат основой для получения более глубоких, специализированных знаний в университете;

- широкое применение приема обобщения полученных знаний. Особенность обучения лингвистов-переводчиков заключается в том, что студенты с помощью обобщения полученных знаний могут впоследствии определять их функциональную направленность. Иными словами, при изучении иностранного языка студенты должны осознавать, что образовательный процесс - не просто совокупность ничем между собой не связанных занятий, но четко структурированный курс, внутри которого существует тесная методологическая связь между его компонентами;

- организация педагогом самостоятельной работы студентов, направленной на получение новых знаний. Педагогу стоит также прививать студентам мысль о том, что язык невозможно зазубрить; его можно научиться чувствовать. Иными словами, педагог направляет свою деятельность на то, чтобы студенты могли бы использовать приобретенные навыки на автоматизме, что может быть обеспечено при организации их самостоятельной работы.

Смешанное обучение сочетает в себе две учебные среды: традиционное обучение в классе и среду дистанционного обучения. Анализ научных публикаций по проблеме исследования позволяет выделить общие 
определения.

В частности, М. Георгсена и К. Ванге-Левстад рассматривают термин «смешанное обучение» через призму единства следующих компонентов:

- применение информационных технологий, которые способствует интерактивному и дистанционному обучению;

- применение педагогических подходов, которые обеспечивают достижение целей образовательного процесса;

- применение таких педагогических технологий, которые предполагают интерактивное взаимодействие между преподавателем и студентами;

- сочетание технологии обучения и практических заданий для достижения баланса между теоретическими и практическими знаниями.

Сегодня данное сочетание традиционных и инновационных методов обучения считается наиболее практичным подходом, поскольку он позволяет студентам пользоваться преимуществами как очного, так и дистанционного обучения. Это утверждение подчеркивают зарубежные ученые М. Оливер, К. Тригвелл, определяющие термин «смешанное обучение» как «... учебный план, в котором учащийся частично учится в режиме онлайн (контролируя время, место, способы и / или темп) и частично в учебном заведении».

Использование онлайн-ресурсов делает изучение дисциплины «Иностранный язык (английский)» привлекательным для студентов за счет интерактивных и мультимедийных аспектов, позволяющих изучать материал в индивидуальном темпе, асинхронно с другими членами группы. В то же время обучение в классе способствует сплоченности группы и формирует чувство принадлежности к команде, способствует живому общению в группе с учителем и учениками и позволяет получить разъяснения и объяснения непосредственно в момент возникновения затруднений.

На основе письменного опроса, проведенного в группах студентов (всего было опрошено около 200 человек), автор проанализировал мотивы, которыми руководствуются студенты специальности «лингвист-переводчик» при изучении английского языка.

На основании полученных результатов мы пришли к выводу, что при изучении английского языка внутренние мотивы студентов преобладают над внешними. В частности, большинство студентов нашего факультета изучает английский язык с целью общения с людьми из англоязычных стран во время путешествий и при осуществлении деловых контактов; они знакомятся со своими сверстниками и начинают писать текстовые сообще- ния в Интернете или болтать в Skype (32\%). Преодоление языкового барьера - важнейшая задача для них.

В первую очередь выдвигается мотив коммуникативного общения. Система обучения английскому языку на кафедре «Лингвистика» направлена в первую очередь на развитие коммуникативных навыков, что является большой заслугой преподавателей кафедры. Столько же студентов (32\%) считают важным мотив поиска престижной работы и карьерного роста.

Многие студенты стремятся самоутвердиться в профессиональном отношении. Многостороннее изучение и основательное знание какого-либо иностранного языка рассматривается студентами как хорошая возможность найти престижную и высокооплачиваемую работу в крупных городах нашей страны или за рубежом.

15\% студентов сделали акцент на обеспечении кросскультурного взаимодействия между различными странами. Поэтому они отметили необходимость хорошо понимать иностранные фильмы, песни, где активно применяется современная разговорная лексика. 19\% студентов ставят перед собой задачу освоение иностранного языка для того, чтобы можно было выполнять различные бизнес- и научные проекты, а также пользоваться различными компьютерными программами.

Среди опрошенных студентов около 6\% выдвинули мотив понимания научно-технических текстов, так как работы многих великих ученых написаны на английском языке. Каждый образованный человек должен уметь читать и понимать инструкции и спецификации по конструкции и работе различных устройств и механизмов, написанные на английском языке.

Некоторые студенты (3\%) считают, что изучение иностранного языка необходимо для обмена информацией между сверстниками, друзьями, знакомыми. 1\% студентов видят цель выучить язык для продолжения обучения за границей; 1\% - потому что английский язык является обязательным предметом в университете; $1 \%$ - потому что у них особый интерес к изучению иностранных языков, им нравится сам процесс обучения. Таким образом, мотивационный аспект важен для активации всех психологических процессов - мышления, восприятия, понимания и усвоения материала иностранного языка.

Вышеперечисленные факторы служат сильными стимулами для студентов переводоведческой специальности детально изучать определенный иностранный язык. Таким образом, педагогу следует продумывать подходы к образовательному процессу, которые позволили бы поддерживать высокий уровень интеллектуальной активности и мотивации студентов. 


\section{Обсужмение}

Таким образом, внедрение метода смешанного обучения на английском языке в технических вузах позволяет добиться высокой степени студенческой работы в недостаточном количестве аудиторий, что позволяет значительно повысить продуктивность изучения дисциплины «Иностранный язык (английский)». BL - один из эффективных способов решения проблемы разработки и внедрения учебных материалов, отвечающих требованиям умного образования. Мы считаем, что внедрение BL в процесс подготовки студентов технических специальностей способствует организации и планированию работы самостоятельно, улучшает качество исследований и понимание академической честности.

\section{Зак^ючение}

Мы увидели, что применение традиционных и инновационных педагогических технологий (которое получило название «смешанное обучение») обеспечивает высокую эффективность образовательного процесса, как для студентов, так и для преподавателей.

Во-первых, на фоне сокращения учебного времени педагог посредством информационных технологий может поддерживать прочную связь со студентами, что дает возможность изучать иностранный язык дополнительно и более основательно. Во-вторых, инновационные технологии позволяют педагогу находить индивидуальный подход к каждому студенту и сократить разрыв в уровне знаний внутри студенческой группы. В-третьих, данный подход соответствует современной тенденции широкого внедрения авторских педагогических технологий, что позволяет выйти образованию в целом на качественно новый уровень.

\section{БлагоАарность:}

Автор выражает признательность сотрудникам кафедры и студентам факультета за оказание помощи в организации и проведении научного исследования.

\section{ЛИТЕРАТУРА}

1. Alkenova S.N. Innovative educational technologies in the context of teaching a foreign language in high school and their competent application // Tendencies of development of science and education. - 2020. - № 64-4. - P. 9-12.

2. Berman I.M. Methods of teaching English in non-language universities. - 2nd ed. - Moscow: Rusyns. - 2015. - 232 p.

3. Georgsena M., Vange Løvstada. Use of blended learning in workplace learning // Procedia - Social and Behavioral Sciences. 2014. -- № 142. - P. 775.

4. Oliver M., Trigwell K., Can 'Blended Learning'Be Redeemed? - URL: http://journals.sagepub.com/doi/abs/10.2304/ elea.2005.2.1.17

5. Sbotova S.V. Linguistic aspect of the study of a foreign language in a technical university (on the question of the influence of linguistic teachings of the XIX-XX centuries on the formation of the modern concept of the English language) [Text] / S.V. Sbotova, 0.S. Milotaeva. - Penza: PGUAS, 2018. - 167 p.

(с) Гецкина Инна Борисовна (igets68@gmail.com). 